\title{
Optimization of a 1mm thick PVA/acrylamide recording material to obtain holographic memories: method of preparation and holographic properties
}

\author{
M. Ortuño ${ }^{1 \mathrm{a}}$, S. Gallego ${ }^{1}$, C. García ${ }^{1}$, C. Neipp ${ }^{2}$, A. Beléndez ${ }^{2}$ and I. Pascual ${ }^{1}$ \\ ${ }^{1}$ Departamento Interuniversitario de Óptica. Universidad de Alicante, \\ Apartado 99. E-03080 Alicante, SPAIN. \\ ${ }^{2}$ Departamento de Física, Ingeniería de Sistemas y Teoría de la Señal. \\ Universidad de Alicante, Apartado 99. E-03080 Alicante, SPAIN. \\ a mos@ua.es
}

\begin{abstract}
Information holographic storage is a very promising technique due to its high theoretical capacity. One of the key factors in developing holographic memories is the need for a suitable recording material which must have certain specific characteristics. In particular, in order to achieve a high storage density it is necessary to work with great thicknesses. One of the essential requirements for holographic memories to be competitive is that the material must have a thickness of $500 \mu \mathrm{m}$ or more, but it is not easy to find such thicknesses with the photopolymers currently available. In this study, we develop a method of preparing layers of a polyvinyl alcohol/acrylamide based photopolymer approximately $1 \mathrm{~mm}$ thick. Optimization of this material makes it possible to obtain good results for the main holographic parameters; diffraction efficiency $70 \%$ and energetic sensitivity $50 \mathrm{~mJ} / \mathrm{cm}^{2}$.
\end{abstract}

PACS numbers: 42.70.Ln; 42.40.Pa; 42.40.Ht

ORTUÑO, Manuel, et al. "Optimization of a $1 \mathrm{~mm}$ thick PVA/acrylamide recording material to obtain holographic 


\section{Introduction}

In recent decades a great deal of research has been carried out in the field of holographic information storage due to the great possibilities of this technology: a maximum theoretical storage capacity 1000 times greater than that of a CDROM, and random access time of only $10 \%$ of the latter [1]. In this type of device, a laser beam contains the information of a bidimensional matrix of ones and zeros, representing digital data, obtained using a computer and a spatial light modulator. This laser beam interferes with a second reference beam to form an interference pattern in the recording material. During the reading stage of the holographic memory, a reading laser beam falls on the interference pattern stored in the recording material and reconstructs the information on a digital chip. For this innovative technology to have industrial application, it is essential to find a suitable recording material.

Photopolymers are one type of compounds that can be used as holographic recording material. They have an acceptable energetic sensitivity, a variable spectral sensitivity depending on the sensitizer dye used, good resolution, high diffraction efficiency and good signal/noise ratio. Their low price, easy preparation and the fact that complicated developing processes are not necessary make them even more attractive for use on a large scale in read only WORM (write once read many) type memories. One type of photopolymers are those based on polyvinyl alcohol (PVA)/acrylamide (AA). In the simplest case they consist of PVA as the polymer matrix, AA as the polymerizable monomer, triethanolamine (TEA) as free radical generator and a sensitizer, in our case yellowish eosin (YE), which allows the material to respond at $514 \mathrm{~nm}$ (Argon laser). One of the basic requirements for holographic memories to be competitive is that the film of recording material must be $500 \mu \mathrm{m}$ or more thick [2]. A greater number of holograms may be recorded with thicker layers, since in this case the angular selectivity is greater due to the fact that the width of the angular response curve is very small [3]. It is not easy to find such great thicknesses with the recording materials currently available: in the case of photographic emulsions and dichromate gelatine, the layers barely reach a thickness of a few tens of micrometers. None of the commercial photopolymers form sufficiently thick layers, and only with acrylate oligomer-based photopolymers [4] and new photopolymers based on organosilanes and their derivatives prepared using the sol-gel technique [5], is it possible to obtain a thickness of over $500 \mu \mathrm{m}$. As far as acrylamide photopolymers are concerned, most of the studies found in the 
bibliography refer to thicknesses of less than $300 \mu \mathrm{m}$ [6] [7]. A summary of the historical evolution of these materials was recently published by Lawrence et al. [8].

In our study we develop a holographic recording material based on PVA/AA. A detailed study of its method of preparation and the factors governing the process enable thicknesses of around $1000 \mu \mathrm{m}$ to be reached. Additionally, optimization of the composition allows good results to be obtained for the main holographic parameters, measured in order to characterize the material, such as diffraction efficiency (DE), energetic sensitivity (S) or the minimum energy required to reach maximum diffraction efficiency (DEmax).

\section{Experimental section.}

\subsection{Preparation of the material}

In recording materials based on PVA/AA, a solution of PVA in water forms the matrix and this is used to prepare the mixture of monomer (AA) and photopolymerization initiator system (TEA, YE). The PVA was supplied by Fluka, AA and TEA by Sigma and YE by Panreac. The mixture is usually deposited in a layer on a glass plate and after evaporation of part of the water, a solid plastic film is formed which constitutes the holographic recording material. The conventional method of depositing the layer consists in using a manual or automatic depositor, which by means of a rod or calibrated opening deposits the solution in a uniformly thick layer on a glass plate [9]. In order to increase the final thickness of the layer, the PVA concentration in the initial solution is increased, since in this way a greater amount of water is retained by the PVA in the "dry" layer. However, this also means that there is a significant increase in the viscosity of the solution. Since there is a limit to the viscosity of the solutions that can be used with the depositors, and bearing in mind the process of preparation and subsequent cutting of the coated plates, the maximum thickness that can be obtained by this method is between 200 and $300 \mu \mathrm{m}$. Therefore, for the application we are interested in, it is necessary to find another method of preparing the layers which enables greater thicknesses to be obtained.

In this study we prepare the solutions using a conventional magnetic stirrer, under red light and in standard laboratory conditions (temperature, pressure, relative humidity). If the viscosity is too high to use a magnetic stirrer, we stir slowly by hand to prevent the formation of air bubbles, followed by the application of a vacuum to both the prepared solution and the 
coated mold so that any eventual air bubbles are completely eliminated. The solutions are deposited, using the force of gravity, in polystyrene or polymethylmethacrylate molds, and left in the dark to allow the water to evaporate, while recording the laboratory conditions (temperature and relative humidity, $\mathrm{RH}$ ) during the process. When part of the water has evaporated, the "dry" material is removed from the mold, cut into squares and adhered, without the need for adhesive, to the surface of glass plates measuring $6.5 \times 6.5 \mathrm{~cm}^{2}$. The plates are then ready for exposure, which takes place immediately. The thickness of the material is measured using a conventional micrometer.

\subsection{Holographic setup}

To study the behavior of the photopolymer as a holographic recording material, we obtained unslanted diffraction gratings using a holographic setup. The experimental device is shown in Figure 1. An Argon laser at a wavelength of $514 \mathrm{~nm}$ was used to store diffraction gratings by means of continuous laser exposure. The laser beam was split into two secondary beams with an intensity ratio of $1: 1$. The diameters of these beams were increased to $1.5 \mathrm{~cm}$ with an expander, while spatial filtering was ensured. The object and reference beams were recombined at the sample at an angle of $16.8^{\circ}$ to the normal with an appropriate set of mirrors, and the spatial frequency obtained was 1125 lines $/ \mathrm{mm}$. The working intensity at 514 $\mathrm{nm}$ was $5 \mathrm{~mW} / \mathrm{cm}^{2}$. The diffracted and transmitted intensity were monitored in real time with a He-Ne laser positioned at Bragg's angle $\left(20.8^{\circ}\right)$ tuned to $633 \mathrm{~nm}$, where the material does not polymerize. In order to obtain transmission and diffraction efficiency as a function of the angle at reconstruction we placed the plates on a rotating stage. The transmission and diffraction efficiency (TE and DE respectively) were calculated as the ratio of the transmitted and diffracted beam, respectively, to the incident power.

\section{Results and Discussion}

2.1 Influence of the characteristics of the polymer binder (PVA)

The different types of commercial PVA are classified according to their molecular weight and degree of hydrolysis, which are the factors that determine the viscosity of the prepared solutions and the polymers' capacity to retain water. The difference in the degree of hydrolysis of the different PVA is small, since they are all hydrolyzed to quite a high degree 
and have a small number of residual acetate groups. The average molecular weight $\mathrm{M}_{\mathrm{w}}$ of the commercial products does, however, vary to a great extent, between 20000 and 200000. PVA with a low average molecular weight have short chains and give solutions of low viscosity and little capacity to retain water per unit of mass. PVA with high average molecular weight usually have very long polymer chains and when dissolved in water give solutions of high viscosity with a great capacity per unit of mass to retain water. The choice of PVA is a fundamental factor in obtaining a material of great thickness. The PVA normally used in the bibliography in studies on the type of photopolymers we are dealing with has a low molecular weight $\left(\mathrm{M}_{\mathrm{w}}=27000\right)$. This type of PVA is not suitable to obtain very thick layers capable of being used in holographic memories, since it has little capacity to retain water, which means that a high concentration is necessary and this hinders the photopolymerization process. Moreover, a great deal of solution must be deposited in order to obtain the required thickness, and given the small amount of water retained, the concentration of active substances in the dry film increases excessively. This gives rise to poor photopolymerization results, since this process depends directly on the concentrations in the film of material and not on the concentrations in the initial solution. On the other hand, a PVA with a high molecular weight has very long polymer chains which give rise to a high light dispersion. This is a factor to be borne in mind in the process of recording and reading the data stored in the material. Consequently, it is necessary to find a type of PVA that allows sufficient water to be retained so as to obtain layers of the required thickness, and has a molecular weight such that the material does not exhibit excessive dispersion of light. In Figure 2, which represents the sum of diffraction efficiency and transmission efficiency (DE+TE) versus exposure time, the behaviour of PVA Fluka 18-88 with an average molecular weight $\mathrm{M}_{\mathrm{w}}=130000$ is compared with that of PVA Fluka 56-98 with an average molecular weight $M_{w}=195000$, in layers 900 $\mu \mathrm{m}$ thick. As can be seen, the curve corresponding to PVA Fluka 18-88 falls more slowly and the values are found to be between $75 \%$ and $85 \%$, whereas the curve corresponding to PVA Fluka 56-98 initially reaches values of $75 \%$ and finally decreases to values of around $45 \%$. This implies that, in the case of the latter PVA, significant losses occur due to absorption and dispersion of light as compared with PVA 18-88, for which the sum DE+TE is higher and stable throughout the holographic processing. This indicates that the losses due to absorption and dispersion are smaller in PVA 18-88, thereby making this material more suitable for our purposes. We did not analyze the behaviour of a PVA with a low molecular weight, since an 
excessively high concentration of the polymer would be necessary to obtain the thickness needed in our study. However, in the bibliography there is a study comparing PVA with a low molecular weight and PVA with an intermediate molecular weight such as Fluka 18-88 in thinner layers [6], in which both types of PVA behave in a similar way in terms of DE+TE values. This gives further support to the choice of Fluka 18-88 as polymer binder.

Table 1 shows the thicknesses achieved $\left(\mathrm{T}=22^{\circ} \mathrm{C}, \mathrm{RH}=45 \%\right)$ with PVA Fluka 18-88 in layers with the following composition of the initial solution : $\mathrm{C}_{\mathrm{PVA}}=13.30 \% \mathrm{w} / \mathrm{v}, \mathrm{C}_{\mathrm{AA}}=0.34 \mathrm{M}$, $\mathrm{C}_{\mathrm{TEA}}=0.15 \mathrm{M}, \mathrm{C}_{\mathrm{YE}}=9 \times 10^{-5} \mathrm{M}$, in which the initial thickness of the liquid layer deposited (LLT) is varied. It can be seen that when the value of LLT increases, so does the final thickness of the resulting layer. If the LLT increases excessively $(0.95 \mathrm{~cm})$, the thickness of the resulting dry layer is not uniform due to the large amount of water evaporated and the big difference between the initial and final thickness. The typical optimum thickness that may be obtained with this composition is $950 \pm 50 \mu \mathrm{m}$, which corresponds to a deposited liquid layer thickness of $0.66 \mathrm{~cm}$, and this is the value chosen for the following trials.

If we increase the concentration of PVA Fluka $18-88$ in the initial solution to $22.79 \% \mathrm{w} / \mathrm{v}$ (a value close to the maximum concentration in solution that can be worked with at room temperature), while maintaining a LLT of $0.66 \mathrm{~cm}$, we obtain layers with a typical thickness of $1200 \mu \mathrm{m}$. When we change the type of PVA to Fluka 56-98, maintaining a concentration of $13.30 \% \mathrm{w} / \mathrm{v}$ and $\mathrm{LLT}=0.66 \mathrm{~cm}$, we obtain a typical layer thickness of $1100 \mu \mathrm{m}$. In both cases it can be seen that the typical thickness of the composition is exceeded, although neither of these options is advisable due to the effect of the dispersion of light mentioned above and poorer results obtained in terms of maximum diffraction efficiency (DEmax), thus minimizing the initial advantage of a somewhat greater thickness.

\subsection{Optimization of the AA/TEA concentration $\left(\mathrm{C}_{\mathrm{PVA}}=13.30 \% \mathrm{w} / \mathrm{v}, \mathrm{C}_{\mathrm{YE}}=9 \times 10^{-5} \mathrm{M}\right)$}

The thickness of the layers of material prepared for exposure determines the monomer concentration necessary to obtain a high efficiency and whether overmodulation occurs or not. Since the diffraction efficiency obtained is affected by the thickness of the material and the index modulation, for a given thickness, it is necessary to adjust the monomer concentration to delimit the refractive index modulation. Moreover, the monomer concentration also determines the TEA concentration to be used, since the AA/TEA ratio is maintained constant in all cases at a value within the optimum range for this type of 
photopolymer [10]. In order to evaluate the influence of the AA concentration, we worked with three different concentrations $(0.41 \mathrm{M}, 0.34 \mathrm{M}, 0.17 \mathrm{M})$, maintaining a constant $\mathrm{C}_{\mathrm{AA}} / \mathrm{C}_{\mathrm{TEA}}=2.27$ ratio. Table 2 shows the values of DEmax and S. Figure 3 shows a typical result for the response of $\mathrm{DE}$ versus $\mathrm{E}$ for trials corresponding to each value of $\mathrm{AA}$ concentration. For $\mathrm{C}_{\mathrm{AA}}=0.34 \mathrm{M}$ the highest value of $\mathrm{DEmax}$ is obtained. $\mathrm{A}$ higher concentration $\mathrm{C}_{\mathrm{AA}}=0.41 \mathrm{M}$ does not give the highest DEmax, while a lower concentration $\mathrm{C}_{\mathrm{AA}}=0.17 \mathrm{M}$ results in a lower DEmax with, moreover, a great deal of energy being needed to obtain this maximum, which means a low sensitivity (higher $\mathrm{S}$ value). Therefore, from Figure 3 it can be deduced that the best results are obtained for a composition with $\mathrm{C}_{\mathrm{AA}}=0.34 \mathrm{M}$. Figure 4 shows the angular response obtained after exposure of the plates prepared using the optimum concentration. The Demax is obtained at Bragg's angle.

\subsection{Optimization of the YE concentration.}

In the very thick layers of recording material needed for information storage applications, the dye concentration must be significantly less than in the case of thinner layers. The reason for this is that a high dye concentration in very thick layers implies that there is a large number of dye molecules, which in turn means that a great amount of light is absorbed and only a small amount penetrates the recording material [2].

Table 3 shows the plates prepared using the following composition: PVA Fluka 18-88 13.30\% $\mathrm{w} / \mathrm{v}, \mathrm{C}_{\mathrm{AA}}=0.34 \mathrm{M}, \mathrm{C}_{\mathrm{TEA}}=0.15 \mathrm{M}$, varying the $\mathrm{YE}$ concentration, and a $\mathrm{LLT}=0.66 \mathrm{~cm}$. Figure 5 shows the DE versus E curve; the dye concentration varies between $12 \times 10^{-5} \mathrm{M}$ and $3 \times 10^{-5} \mathrm{M}$. There is an optimum value for $\mathrm{C}_{\mathrm{YE}}=9 \times 10^{-5} \mathrm{M}$, the region in which DEmax attains its greatest value. In most of the trials, an excessively high dye concentration $\left(\mathrm{C}_{\mathrm{YE}}=12 \times 10^{-5} \mathrm{M}\right)$ leads to a lower diffraction efficiency, a great deal of dispersion and a large number of irregularities in the DE versus E graph. A dye concentration of less than the optimum results in a lower DEmax, as occurs with $\mathrm{C}_{\mathrm{YE}}=6 \times 10^{-5} \mathrm{M}$ and $\mathrm{C}_{\mathrm{YE}}=3 \times 10^{-5} \mathrm{M}$, since the presence of a smaller number of molecules capable of initiating polymer chains leads to a low level of polymerization and, therefore, a decrease in diffraction efficiency. The trials carried out with the highest dye concentration show a high percentage of results with a lower DE than that obtained using the optimum concentration, together with a greater dispersion of light (as in the case shown for $\mathrm{C}_{\mathrm{YE}}=12 \times 10^{-5} \mathrm{M}$ ). However, a very small percentage of results are better (higher DEmax, lower S, less dispersion) than those obtained with the optimum 
concentration. This could be due to a statistical phenomenon in which the orientation of the dye molecules in the material or a lower local concentration may have a certain influence. A lower local concentration of dye molecules or an orientation that produces a screening of the incident light, may result in a reduction in the effective local dye concentration. This would make the effective local concentration decrease until it falls within the optimum range, thereby obtaining satisfactory results ( in 11 trials, these characteristics were found in 2). The optimum value $\mathrm{C}_{\mathrm{YE}}=9 \times 10^{-5} \mathrm{M}$ is almost ten times less than that used in thicknesses of up to $200 \mu \mathrm{m}[11]$.

\subsection{Process window}

Once the layers are sufficiently dry, they undergo holographic processing. The presence of water and PVA in the composition of the material and the way it is prepared, using a solution from which a certain amount of water is progressively evaporated, have a decisive effect on the characteristics of the material. From the moment the initial solution is prepared to the moment the material becomes a solid film and is considered "dry", water is continuously evaporated. When the holographic processing takes place, the material continues to exchange water with the atmosphere. The rate of evaporation depends on the relative humidity and this has a direct effect on the drying time and formation of the solid film, since a greater relative humidity implies a longer drying time. From the time the solid layer is dry enough to be handled and holographically processed to the time the material is deformed due to an excessive loss of water, there is an interval in which holographic processing is possible. This interval of time can vary between a few hours and several days depending on the relative humidity in the atmosphere. The optimum moment to develop the plates is when they are just dry enough to be handled. If the holographic processing is performed after the optimum moment (in the worst case, with low relative humidity, after just a few hours) poorer results are obtained. The first parameter to be negatively affected is the energetic sensitivity, while the maximum diffraction efficiency is also reduced is we wait too long after the optimum point. Table 4 shows the best results obtained for plates of material with the following composition of initial solution: . $\mathrm{C}_{\mathrm{PVA}}=13.30 \% \mathrm{w} / \mathrm{v}, \mathrm{C}_{\mathrm{AA}}=0.34 \mathrm{M}, \mathrm{C}_{\mathrm{TEA}}=0.15 \mathrm{M}, \mathrm{C}_{\mathrm{YE}}=9 \times 10^{-5}$ $\mathrm{M}$, varying only the laboratory conditions in which the layers were dried. It can be seen that in the case of a relative humidity of $60 \%$, when the holographic processing was prolonged an extra day (plates C-G as compared with plates A-B), the energy needed to reach DEmax is 
greater (almost twice as much). With plate $\mathrm{H}$, due to the lower relative humidity, the drying time is less, but the best value of sensitivity is higher. These results can be explained bearing in mind that in the case of higher relative humidity, one day's difference in the processing time changes the sensitivity by a factor of $100 \%$, whereas in the case of a more energetic drying, a few hours' difference in the drying time may mean that we are quite far away from the optimum point, and the best results obtained are values of sensitivity which are much higher than expected, as occurred with plate $\mathrm{H}$.

Variations in drying time also affect the maximum diffraction efficiency reached. Figure 6 shows the results obtained for a sample of 20 trials with drying times of 13 and 14 days $(60 \%$ $\mathrm{RH}, 25^{\circ} \mathrm{C}$ ). The percentage of trials that reach certain values of maximum diffraction efficiency is shown. It can be seen that a higher value of DEmax (about 70\%) is obtained with the shorter drying time (13 days). A somewhat longer drying time than the optimum (14 days) results in a lower value of DEmax $(60 \%)$ although there is more uniformity in the values obtained

We shall now describe the evolution of the drying of a layer of material from the moment the solution is deposited to the moment the solid film is formed. This follow-up will enable us to determine the optimum drying time. The prepared solution has the following composition: PVA Fluka 18-88 $\mathrm{C}_{\mathrm{PVA}}=13.30 \% \mathrm{w} / \mathrm{v}, \mathrm{C}_{\mathrm{AA}}=0.34 \mathrm{M}, \mathrm{C}_{\mathrm{TEA}}=0.15 \mathrm{M}, \mathrm{C}_{\mathrm{YE}}=9 \times 10^{-5} \mathrm{M}$. The solution is coated on an open mold in the dark. During the experiment, the evolution of mass with time is observed and the material is weighed at intervals under red light. Care is taken at all times to maintain the relative humidity and temperature as constant as possible, and these two parameters were also followed up. Figure 7 shows the evolution of temperature and relative humidity throughout the experiment: temperature $23 \pm 2{ }^{\circ} \mathrm{C}$ and $\mathrm{RH} 64 \pm 10 \%$. Figure 8 shows the temporal evolution of the mass coated on the mold. The mass decreases as a result of loss of water due to evaporation as the dry film of material is formed. At point 1 , corresponding to $10.34 \mathrm{~g}$, the material now forms a solid film. At point $2(8.12 \mathrm{~g})$, the material is deformed when we try to remove it from the mold. At point 3 (7.72 g), the material can be easily removed from the mold and mechanically manipulated. Between points 2 and 3, there is an optimum point at which the layer of material may be removed from the mold, handled and processed holographically. At point 4 the material contracts due to loss of water. Between the optimum point at which to remove the material from the mold and that at which the loss of water due to evaporation is minimum, holographic processing may be 
performed. However, it should be remembered that the further we move away from the optimum point, the poorer the results obtained - first of all there is a reduction in sensitivity and then a decrease in the maximum diffraction efficiency. The explanation for these phenomena can be found in the fact that a lower concentration of water in the "dry" layer hinders the movement of molecules of the species in solution and increases the diffusion coefficients. This has a great effect on the energetic sensitivity, since the rate of polymerization is reduced. If the concentration of water in the "dry" layer decreases far below the optimum value, there is also an excessive increase in the concentration of monomer, radical generator and dye. This implies a low diffraction efficiency and the presence of strange peaks and other alterations on the exposure curves. In the same experiment, carried out at a lower relative humidity (usually around 45\%), it was seen that the processing interval is considerably reduced with the result that it is more difficult to situate ourselves at the optimum point: just a few hours' difference can have a great effect on the results. This behaviour in the process window, with a very short optimum interval (which becomes even smaller as the relative humidity decreases) is partly responsible for the lack of reproducibility associated with this type of material. In order to achieve greater reproducibility and better results for the holographic parameters, the exact optimum processing point should be determined and the drying conditions (RH y T) strictly controlled.

Table 6 shows two examples ( 1 and 2 ) of the main holographic parameters obtained with this recording material, the first for a thickness of $800 \mu \mathrm{m}$ and the second for a thickness of 1160 $\mu \mathrm{m}$. Figures 9 and 10 show the holographic response of diffraction efficiency versus energy of exposure (E) and versus angle at reconstruction of the grating, respectively, for example 1 in Table 6. The maximum diffraction efficiency is about $70 \%$ at $50 \mathrm{~mJ} / \mathrm{cm}^{2}$.

\subsection{Angular multiplexing}

In order to evaluate the material capacity for the record of many diffraction gratings, in Figure 11 we recorded 7 diffraction gratings in the same zone of a $700 \mu \mathrm{m}$ thick recording material using the angular multiplexing technique and reducing by $0.5^{\circ}$ the angle between the perpendicular to the photopolymer layer and the initial position at the Bragg angle, between recording one diffraction grating and the next. In this way a variation of $4.5^{\circ}$ in rotation of the axis perpendicular to the work bench is sufficient to include the 7 gratings. We obtained high values for each individual maximum DE, sufficient separation between the gratings to enable 
their independent reconstruction, and good dynamic range ( $\mathrm{M} \#=25.91)$. A more complete study is in progress.

\section{Conclusion}

We have developed a method of preparing layers of recording material around $1000 \mu \mathrm{m}$ thick, achieved a better understanding of the most important factors involved in the preparation of the material and optimized the concentration of the components. Table 5 shows a summary of the most important parameters in the preparation of the recording material. We studied the holographic behaviour of the material, together with its response in the recording of diffraction gratings, and obtained good results for the main holographic parameters: Demax $=70 \%, \mathrm{~S}=50 \mathrm{~mJ} / \mathrm{cm}^{2}$ and angular response. We used angular multiplexing to store various diffraction gratings in the same material volume, and obtained high individual values of DE. Considering the results obtained and the potential of the material for recording multiple diffraction gratings, the authors believe that this material may have application in digital information storage. However, further studies should be done concerning the possibilities of multiplexing, recovery of stored data, improvement of the resistance of the material to laboratory conditions and the development of practical devices to record and read data.

\section{Acknowledgment}

This work was supported by the Ministerio de Ciencia y Tecnología, CICYT, Spain, under project MAT2000-1361-C04-04.

\section{References}

1. P. J. Van Heeden: Applied Optics 2-4, 393 (1963)

2. H. J. Coufal, D. Psaltis: Holographic Data Storage (G. T. Sincerbox, Springer-Verlag, New York 2000)

3. H. Kogelnik: Bell Systems Technology Journal 48, 2909 (1969)

4. J. E. Boyd, T. J. Trentler, K. W. Rajeev, Y. I. Vega-Cantu, V. L. Colvin: Applied Optics 39-14, 2353 (2000) 
5. P. Cheben, M. L. Calvo: Applied Physics Letters 78-11, 1490 (2001)

6. I. Pascual, C. García, M. Ortuño, S. Gallego, A. Beléndez: OPTO International Conference Optoelectronics, Optical Sensors and Measuring Techniques (AMA Service GmbH, Wunstorf 2002)

7. S. Martin, P. E. Leclere, Y. L. Renotte, V. Toal, Y. F. Lion: Optical Engineering 3312, 3942 (1994)

8. J. R. Lawrence, F. T. O’Neill, J. T. Sheridan: Optik, 112-10, 449 (2001)

9. C. García, I. Pascual, A. Fimia: Boletín de la Sociedad Española de Cerámica y Vidrio 39, 435 (2000)

10. S. Blaya: Estudio y desarrollo de nuevos materiales fotopoliméricos aplicados al almacenamiento óptico de información-Tesis Doctoral (Universidad Miguel Hernández, Elche 2001)

11. M. Ortuño, S. Gallego, C. García, A. Beléndez, I. Pascual: ICO XIX, $19^{T H}$ Congress of the International Commission for Optics (OIC, Florence 2002) 
Table 1. Thickness of the material obtained as a function of the layer of solution deposited

\begin{tabular}{|c|c|}
\hline $\begin{array}{c}\text { Initial liquid layer thickness } \\
(\text { LLT) }\end{array}$ & $\begin{array}{c}\text { Resulting “dry" material } \\
\text { thickness }\end{array}$ \\
\hline$(\mathrm{cm})$ & $(\mu \mathrm{m})$ \\
\hline 0.47 & $800 \pm 20$ \\
\hline 0.66 & $950 \pm 50$ \\
\hline 0.95 & $1500 \pm 500$ \\
\hline
\end{tabular}

Table 2. DEmax and $\mathrm{S}$ when $\mathrm{C}_{\mathrm{AA}}$ and $\mathrm{C}_{\mathrm{TEA}}$ vary for layers with a mean thickness of $950 \pm 50$ $\mu \mathrm{m}$

\begin{tabular}{|c|c|c|c|}
\hline $\mathrm{C}_{\mathrm{AA}}$ & $\mathrm{C}_{\text {TEA }}$ & DEmax & $\mathrm{S}$ \\
\hline$(\mathrm{M})$ & $(\mathrm{M})$ & $(\%)$ & $\left(\mathrm{mJ} / \mathrm{cm}^{2}\right)$ \\
\hline 0.41 & 0.18 & $30-51$ & $100-200$ \\
\hline 0.34 & 0.15 & $34-66$ & $150-200$ \\
\hline 0.17 & 0.0751 & $35-60$ & 700 \\
\hline
\end{tabular}

Table 3. DEmax and $\mathrm{S}$ when $\mathrm{C}_{\mathrm{YE}}$ varies for layers with a mean thickness of $950 \pm 50 \mu \mathrm{m}$

\begin{tabular}{|c|c|c|}
\hline $\mathrm{C}_{\mathrm{YE}}$ & DEmax & $\mathrm{S}$ \\
\hline$(\mathrm{M})$ & $(\%)$ & $\left(\mathrm{mJ} / \mathrm{cm}^{2}\right)$ \\
\hline $12 \times 10^{-5}$ & $10-40$ & $400-900$ \\
\hline $9 \times 10^{-5}$ & $38-59$ & $225-500$ \\
\hline $6 \times 10^{-5}$ & $20-35$ & $200-1000$ \\
\hline $3 \times 10^{-5}$ & $4-10$ & $150-500$ \\
\hline
\end{tabular}

Table 4. DEmax and S varying the drying time in layers with a mean thickness of $950 \pm 50$ $\mu \mathrm{m}$

\begin{tabular}{|c|c|c|c|c|c|}
\hline Code & Drying time & T & RH & DEmax & S \\
\hline & (days) & $\left({ }^{\circ} \mathrm{C}\right)$ & $(\%)$ & $(\%)$ & $\left(\mathrm{mJ} / \mathrm{cm}^{2}\right)$ \\
\hline A & 13 & 25 & 60 & 70 & 40 \\
\hline B & 13 & 25 & 60 & 60 & 35 \\
\hline C & 14 & 25 & 60 & 60 & $88-90$ \\
\hline D & 14 & 25 & 60 & 64 & 79 \\
\hline E & 14 & 25 & 60 & 60 & 80 \\
\hline F & 14 & 25 & 60 & 56 & 84 \\
\hline G & 14 & 25 & 60 & 67 & 98 \\
\hline H & 6 & 20 & 47 & 66 & 150 \\
\hline
\end{tabular}

ORTUÑO, Manuel, et al. "Optimization of a $1 \mathrm{~mm}$ thick PVA/acrylamide recording material to obtain holographic memories: method of preparation and holographic properties". Applied Physics B: Lasers and Optics. Vol. 76, No. 8 (July 2003). ISSN 0946-2171, pp. 851-857 
Table 5. Optimized composition of PVA/AA photopolymer used as holographic recording material and parameters to be considered in its preparation.

\begin{tabular}{|l|l|}
\hline ACRYLAMIDE (AA) & $0.34 \mathrm{M}$ \\
\hline TRIETHANOLAMINE (TEA) & $0.15 \mathrm{M}$ \\
\hline YELLOWISH EOSIN (YE) & $9.0 \times 10^{-5} \mathrm{M}$ \\
\hline POLYVINYLALCOHOL (PVA Fluka 18-88) & $13.30 \% \mathrm{w} / \mathrm{v}$ \\
\hline Liquid layer thickness (LLT) & $0.66 \mathrm{~cm}$ \\
\hline Drying temperatura & $20-25 \quad{ }^{\circ} \mathrm{C}$ \\
\hline Drying time & $\begin{array}{l}\text { Variable depending on the relative } \\
\text { humidity. It is important not to exceed } \\
\text { the optimum time. Example: (RH 60\%, } \\
\mathrm{T}=25{ }^{\circ} \mathrm{C}, \mathrm{P}=1 \text { Atm) 192 hours, 26 } \\
\text { minutes }\end{array}$ \\
\hline
\end{tabular}

Table 6. Maximum diffraction efficiency (DEmax) and energetic sensitivity (S) for two PVA/AA photopolymer layer thicknesses: $800 \mu \mathrm{m}$ (example 1) and $1160 \mu \mathrm{m}$ (example 2)

\begin{tabular}{|l|l|}
\hline Example 1 & \\
\hline Material thickness & $800 \mu \mathrm{m}$ \\
\hline DEmax & $70 \%$ \\
\hline S & $50 \mathrm{~mJ} / \mathrm{cm}^{2}$ \\
\hline Example 2 & \\
\hline Material thickness & $1160 \mu \mathrm{m}$ \\
\hline DEmax & $66 \%$ \\
\hline S & $79 \mathrm{~mJ} / \mathrm{cm}^{2}$ \\
\hline
\end{tabular}


Figure captions

Figure 1. Experimental setup: BS, beamsplitter, Mi, mirror, SFi, spatial filter, Li, lens, Di, diaphragm, PC, data recorder.

Figure 2. Transmission efficiency (TE) plus diffraction efficiency (DE) versus exposure time for two PVA: Fluka 56-98 and Fluka 18-88

Figure 3. Diffraction efficiency (DE) versus exposure (E) for different AA concentrations in layers with $\mathrm{C}_{\mathrm{PVA}}=13.30 \% \mathrm{w} / \mathrm{v}$ in the initial solution

Figure 4. Diffraction efficiency (DE) versus angle of reconstruction for layers with $\mathrm{C}_{\mathrm{AA}}=0.34$ $\mathrm{M}$ and $\mathrm{C}_{\mathrm{PVA}}=13.30 \% \mathrm{w} / \mathrm{v}$ in the initial solution

Figure 5. Diffraction efficiency (DE) versus exposure (E) for different YE concentrations in layers with $\mathrm{C}_{\mathrm{PVA}}=13.30 \% \mathrm{w} / \mathrm{v}$ in the initial solution

Figure 6. Percentage of trials with different DEmax values according to drying time

Figure 7. Variation in room temperature and relative humidity as a function of time in the drying experiment.

Figure 8. Variation in mass with time in the drying experiment

Figure 9. DE versus E for the photopolymer in example 1: thickness of $800 \mu \mathrm{m}$.

Figure 10. Diffraction efficiency (DE) versus angle at reconstruction for the photopolymer in example 1: thickness of $800 \mu \mathrm{m}$.

Figure 11. Diffraction efficiency (DE) versus angle at reconstruction for $700 \mu \mathrm{m}$ layer in multiple gratings recording. 
Figure 1

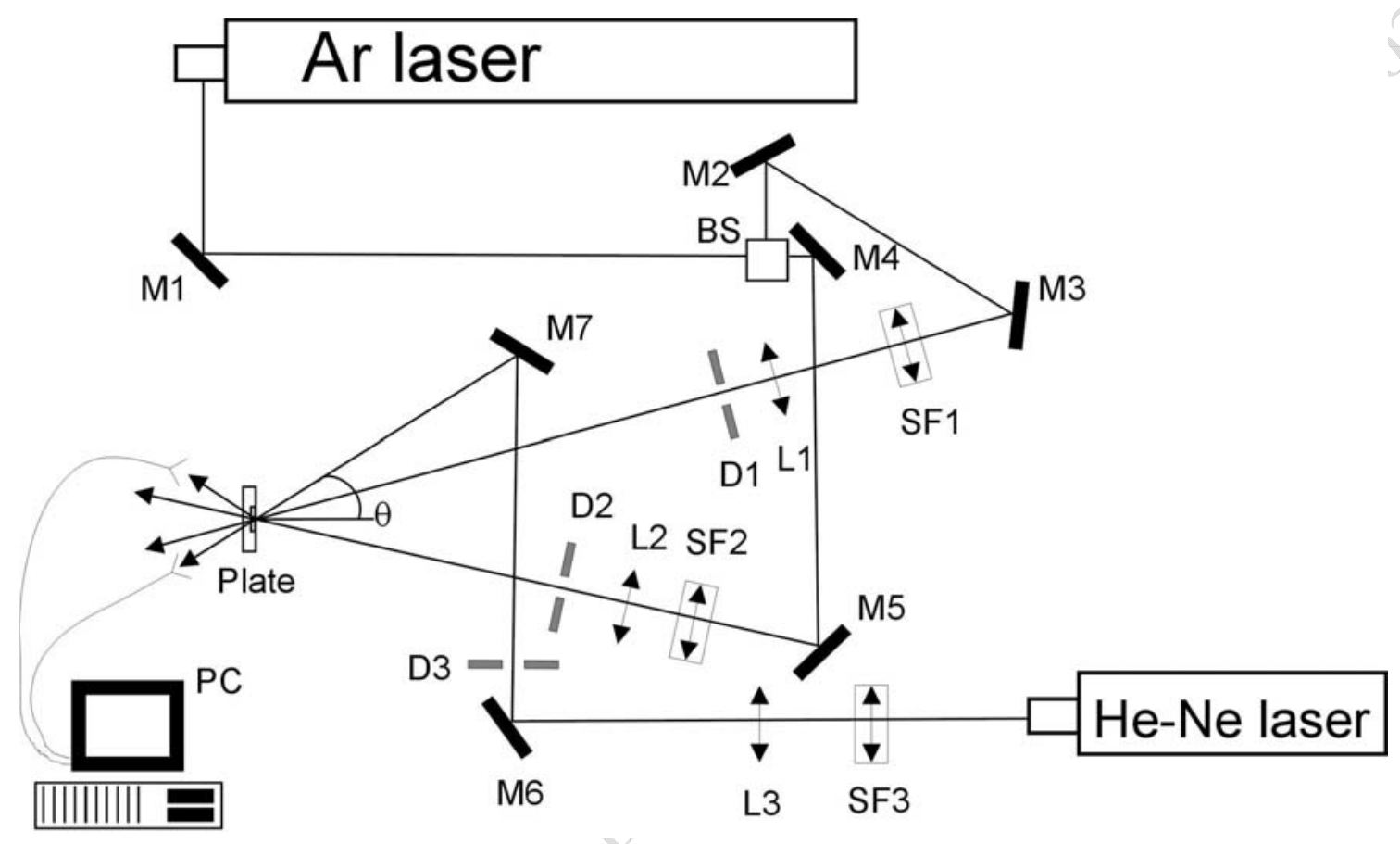

ORTUÑO, Manuel, et al. "Optimization of a $1 \mathrm{~mm}$ thick PVA/acrylamide recording material to obtain holographic memories: method of preparation and holographic properties". Applied Physics B: Lasers and Optics. Vol. 76, No. 8 (July 2003). ISSN 0946-2171, pp. 851-857 
Figure 2

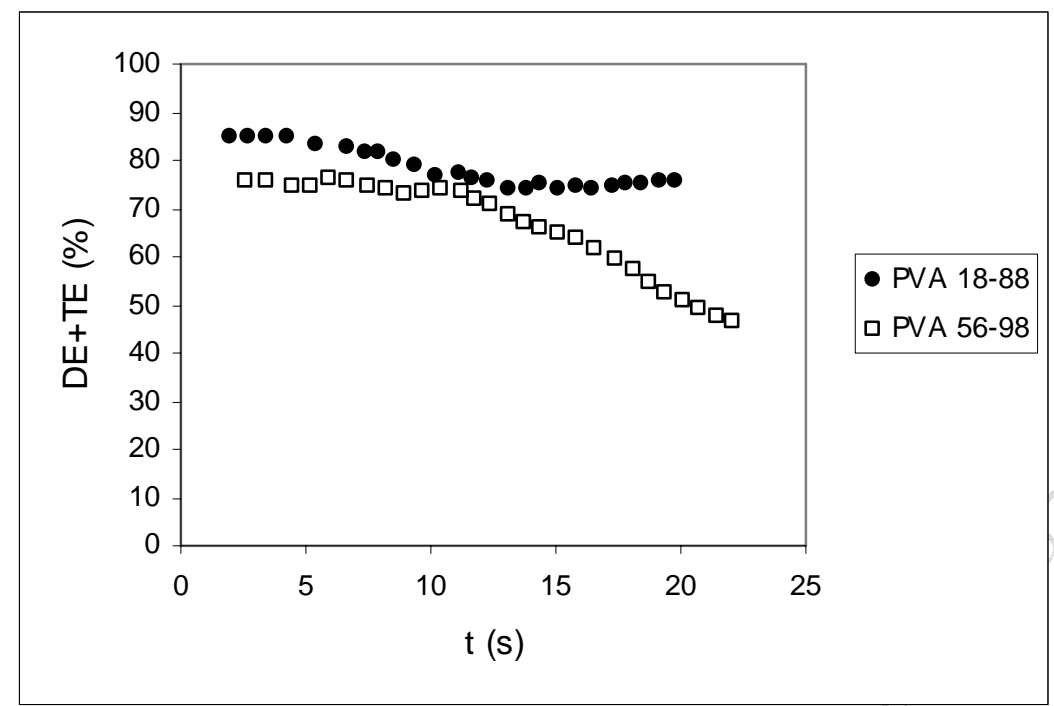

Figure 3

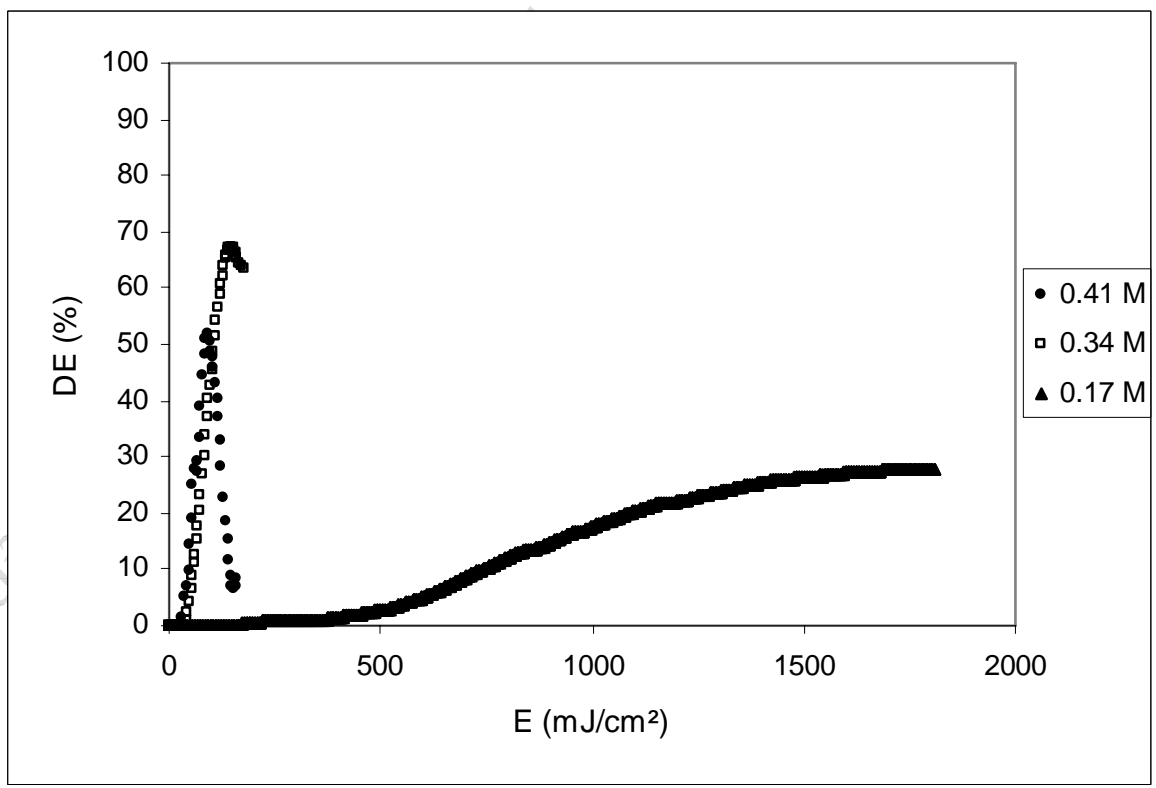

ORTUÑO, Manuel, et al. "Optimization of a $1 \mathrm{~mm}$ thick PVA/acrylamide recording material to obtain holographic memories: method of preparation and holographic properties". Applied Physics B: Lasers and Optics. Vol. 76, No. 8 (July 2003). ISSN 0946-2171, pp. 851-857 
Figure 4

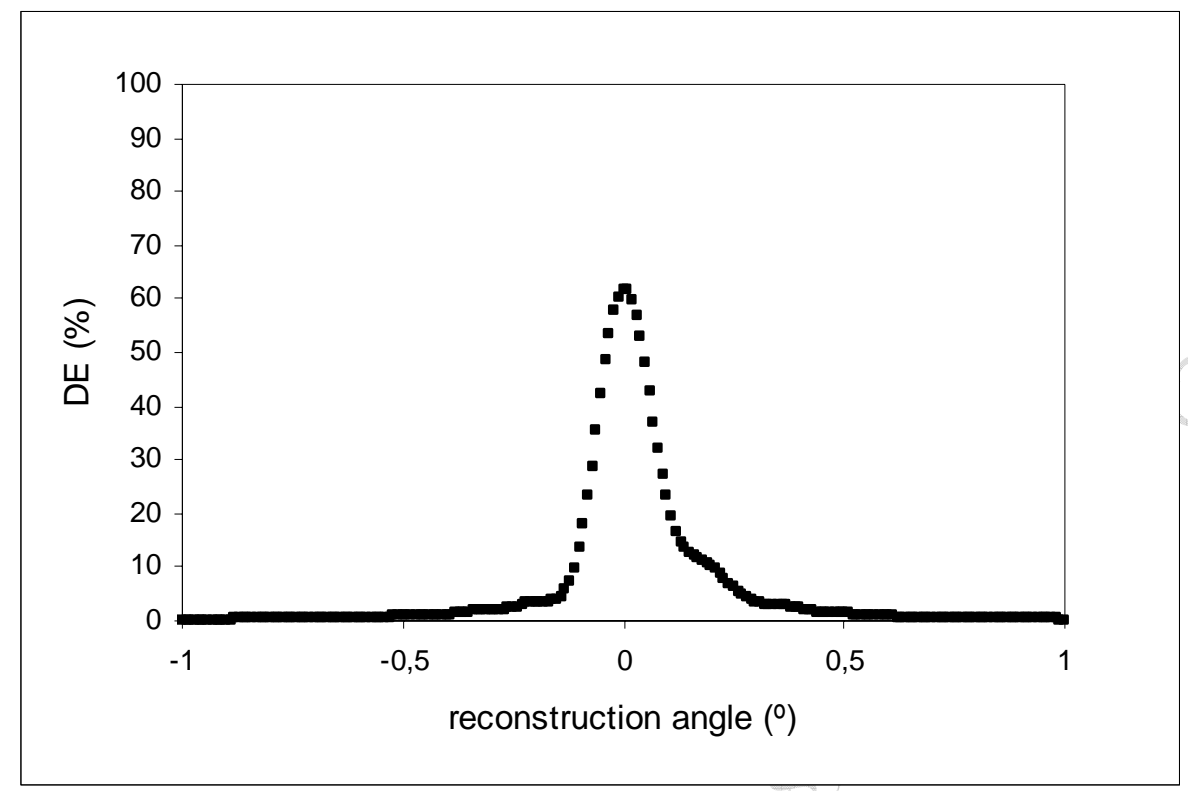

Figure 5

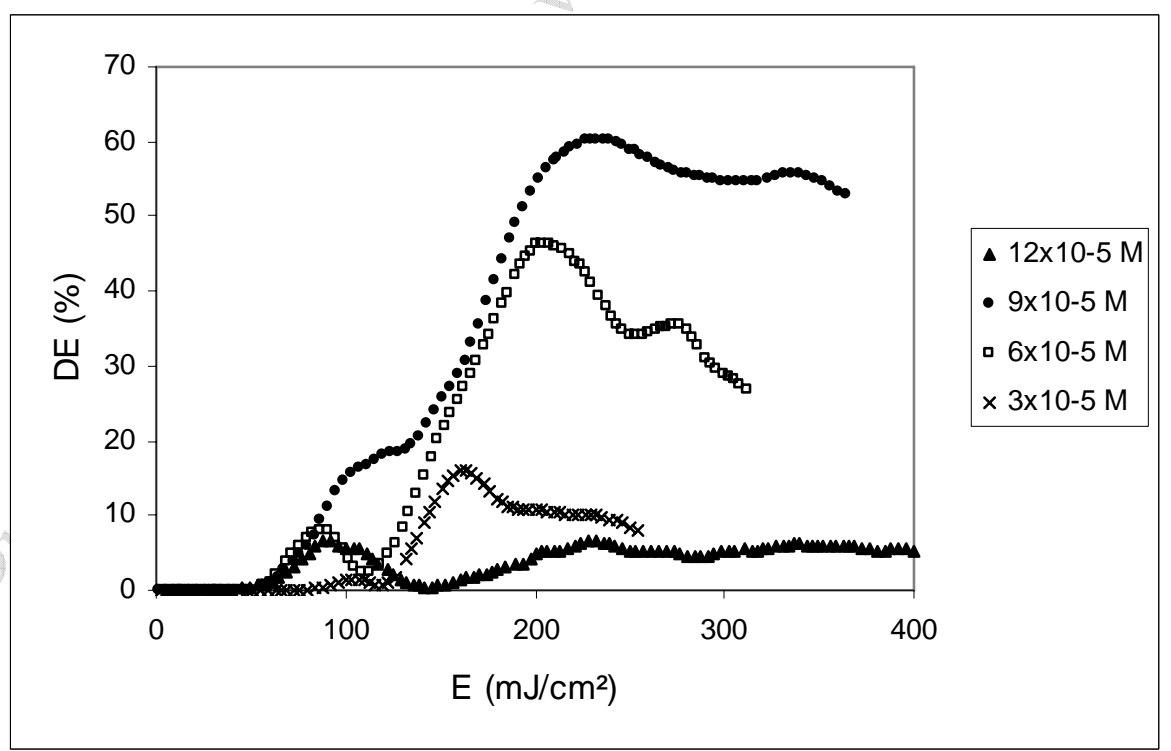

ORTUÑO, Manuel, et al. "Optimization of a $1 \mathrm{~mm}$ thick PVA/acrylamide recording material to obtain holographic memories: method of preparation and holographic properties". Applied Physics B: Lasers and Optics. Vol. 76, No. 8 (July 2003). ISSN 0946-2171, pp. 851-857 
Figure 6

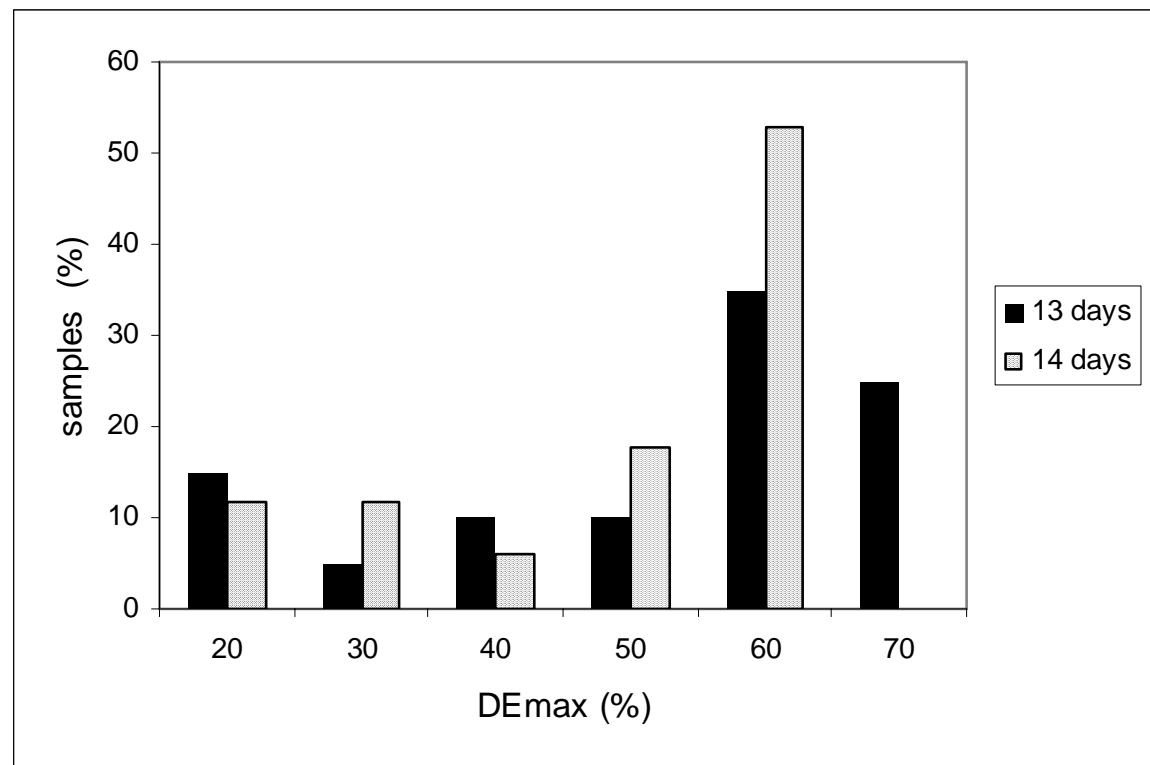

Figure 7

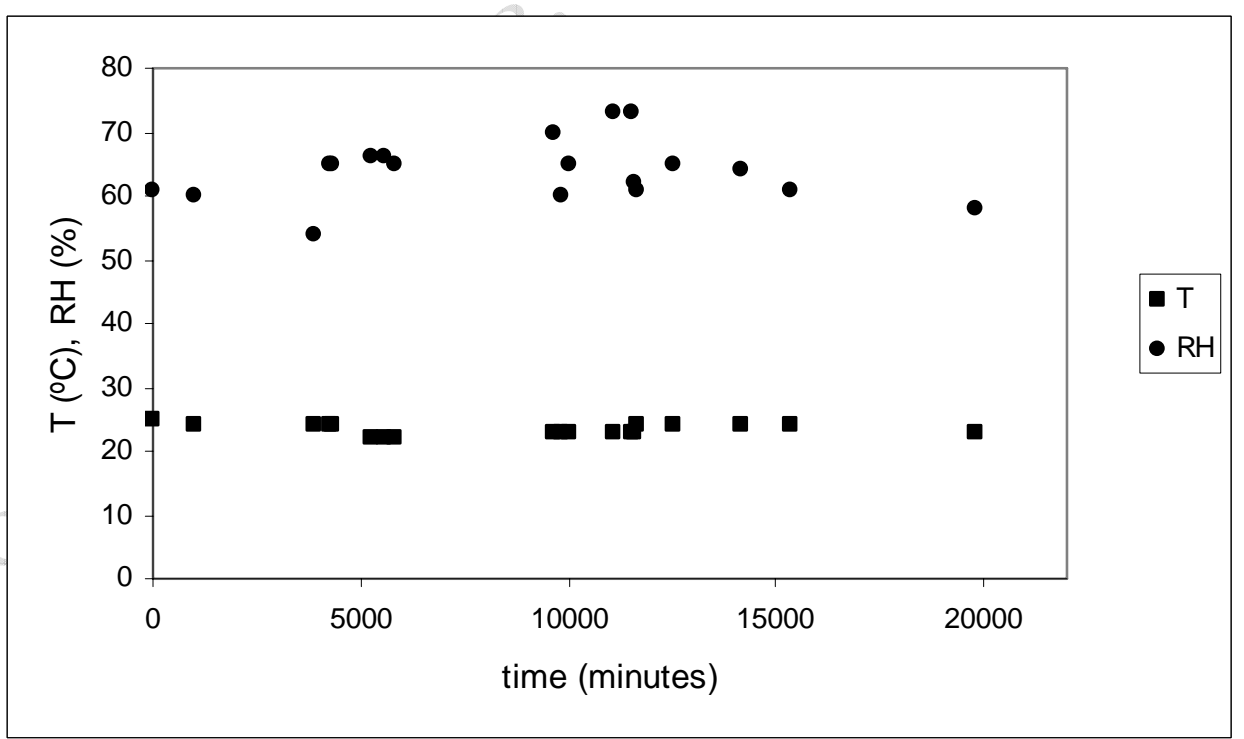

ORTUÑO, Manuel, et al. "Optimization of a $1 \mathrm{~mm}$ thick PVA/acrylamide recording material to obtain holographic memories: method of preparation and holographic properties". Applied Physics B: Lasers and Optics. Vol. 76, No. 8 (July 2003). ISSN 0946-2171, pp. 851-857 
Figure 8

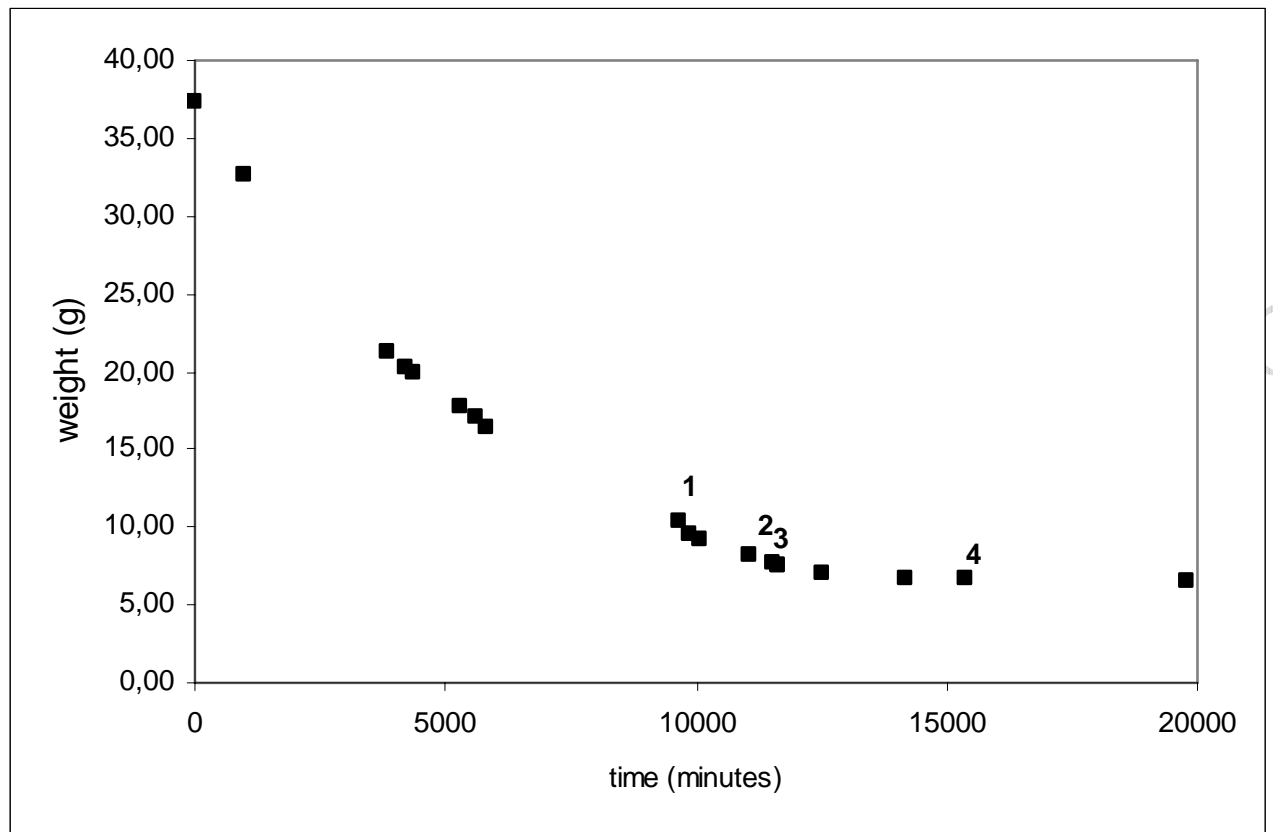

Figure 9

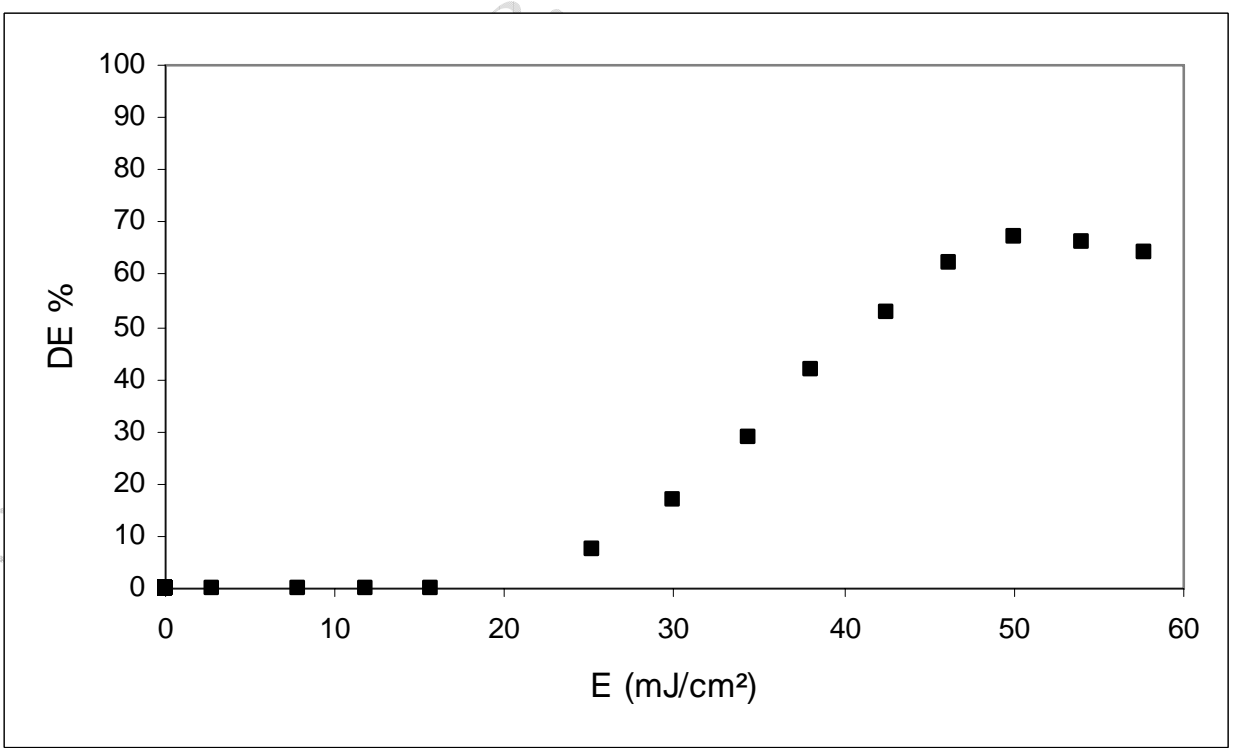

ORTUÑO, Manuel, et al. "Optimization of a $1 \mathrm{~mm}$ thick PVA/acrylamide recording material to obtain holographic memories: method of preparation and holographic properties". Applied Physics B: Lasers and Optics. Vol. 76, No. 8 (July 2003). ISSN 0946-2171, pp. 851-857 
Figure 10

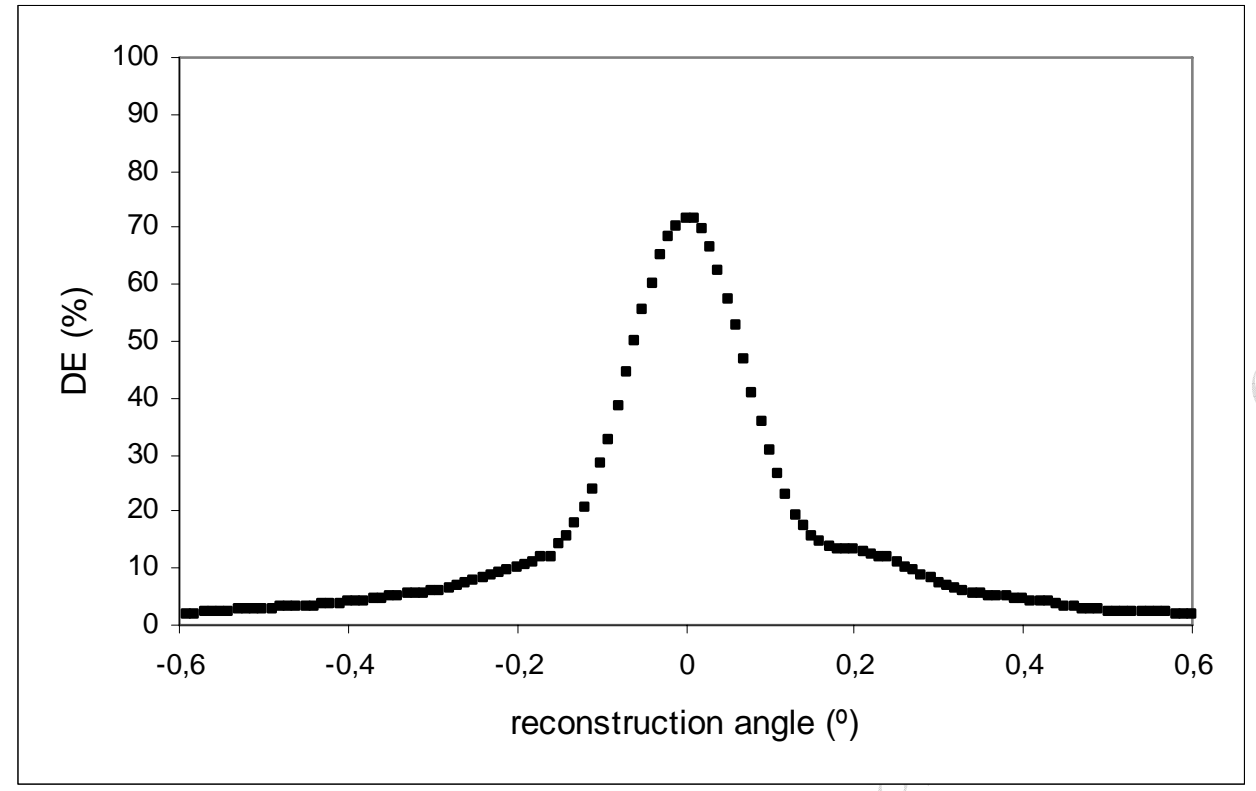

Figure 11

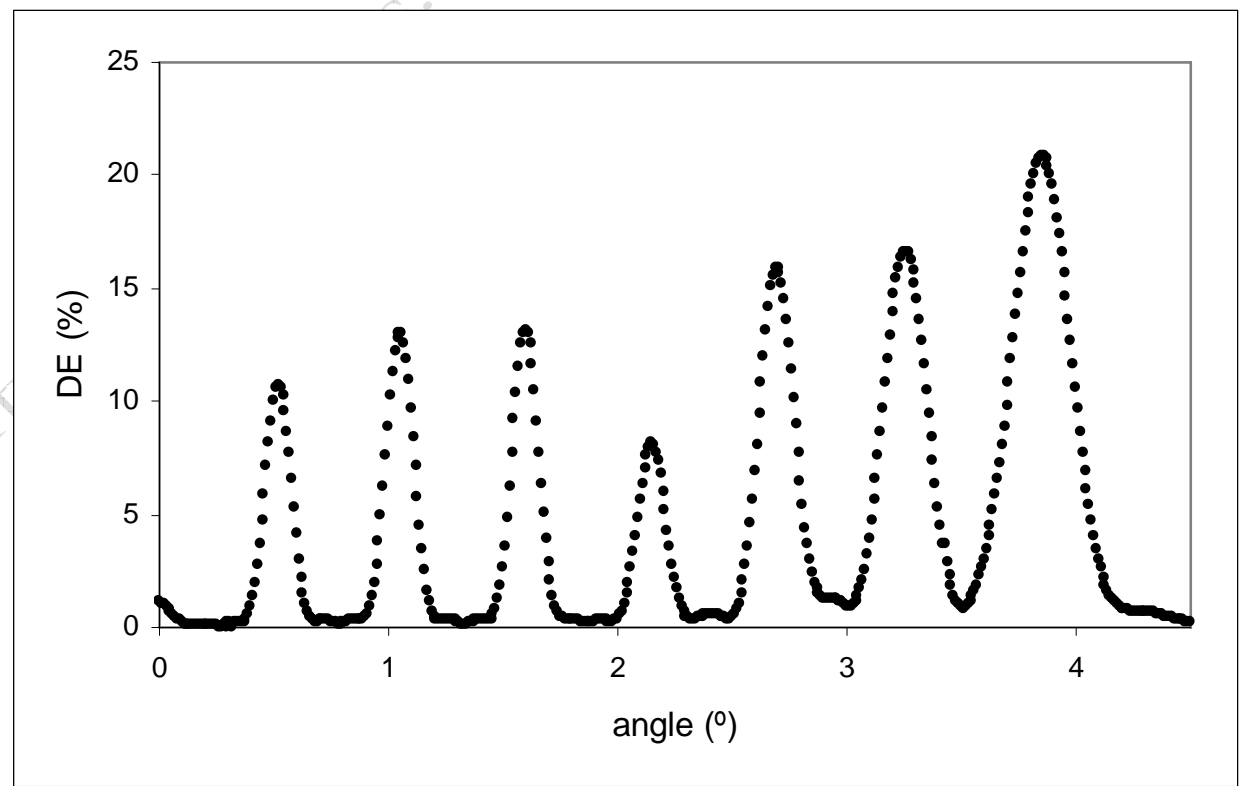

ORTUÑO, Manuel, et al. "Optimization of a $1 \mathrm{~mm}$ thick PVA/acrylamide recording material to obtain holographic memories: method of preparation and holographic properties". Applied Physics B: Lasers and Optics. Vol. 76, No. 8 (July 2003). ISSN 0946-2171, pp. 851-857 